\title{
AN INVESTIGATION INTO THE AETIOLOGY AND PATHOLOGY OF FIBROSITIS OF THE BACK *
}

BY

\section{W. H. MYLECHREEST}

The aetiology and pathology of fibrositis of the back are still unknown, and this investigation was started in the hope of clarifying the picture. It was therefore decided to examine the backs of all bodies reaching the post-mortem table to establish the normal condition before studying any "fibrositic" nodules that might subsequently be available for examination. Twleve backs were dissected. The results set out below appear to have a bearing on the aetiology and pathology of fibrositis of the back.

The twelve backs examined were those of the first twelve bodies which came to post-mortem examination after it had been decided to carry out this investigation. They included, besides cases of longstanding illness and consequently much wasting, several cases of sudden death. As the findings were constant in all twelve bodies they may be regarded as normal and not the result of wasting or the processes of disease. The important part that fatty tissue might play in the disease became apparent after examination of the first few backs. Additional evidence was provided by the clinical experience recorded by W. S. C. Copeman and W. L. Ackerman (1944), who gave me the opportunity to see their cases and to study biopsy material.

\section{Some Definitions}

For the purpose of description it was decided to divide the back into three zones: (1) from the neck down to the lower costal margin; (2) from the lower costal margin to the iliac crest; (3) the buttocks. The most striking feature of these dissections was the distribution of fatty tissue apart from the subcutaneous fat. This was constant in all the bodies, and inasmuch as many of them had little or no subcutaneous fat may be called the " basic fat." Before describing the distribution of this fat it is necessary to describe the fascia of the back. The commonly accepted definition of the superficial fascia is " that areolar tissue which lies immediately beneath the skin." This tissue extends over the entire surface of the body and contains a variable amount of fatty tissue, but, to quote Gray's Anatomy (27th edition, p. 523), " beneath the fatty layer there is generally another layer of superficial fascia, almost devoid of adipose tissue." Furthermore this fascia varies in thickness in different parts of the body-e.g. Scarpa's fascia and Colles' fascia. In the back, too, it con* This article is based on a thesis for the M.D. of Cambridge University. sists not only of one layer but of many layers and compartments, and it is in this fascia that the " basic fat" is found. The term superficial fascia will therefore in this article be restricted to this second or deeper superficial fascia. Deep to this superficial fascia is the deep lumbar fascia, which consists of three layers-posterior, middle, and anterior. The posterior and middle layers unite at the edge of M. Sacrospinalis to form a sheath for the muscle. The fat enclosed in the angle thus formed plays an important part in "fibrositis" of the back, as will be apparent later.

To save needless repetition all the constant findings have been included in one composite description and isolated findings of importance described separately.

\section{ZONE 1}

It was noted that the superficial fascia in the region of the shoulder gets thicker as it ascends to the top of M. Deltoideus, and there are deposits of yellow fat in the upper and posterior aspects of the joint. This fat, which presumably protects the joint, tends to lie deep to the fascia and to run into the intermuscular septa. The superficial fascia thickens into a stout band superficial to the posterior aspect of the acromion and the superior border of the scapula. Fatty tissue is also to be found along these areas. This fascia is very tough and adherent to the skin in this zone, except between the scapulae. A thick fibrous fascia (deep fascia) was found over M. Infraspinatus, with fibres just visible to the naked eye running downwards and outwards. It was attached firmly to the medial border of the scapula and to the scapular spine, and forms a capsule for the muscle. Some fat was found along the spine, deep to this fascial attachment. At the anterior border of M. Trapezius it was seen that the fascia split to enclose the muscle, and in the angle thus formed by the two layers of fascia there was some fatty tissue.

The fat in Zone 1 is almost entirely yellow in colour, in striking contrast to that in Zone 2. It is mostly deep to the superficial fascia and is found chiefly on the inner side of the scapula and the point of the shoulder. There is also yellow and pink fat lying in the sheaths of the tendinous portions of the erector spinae muscles deep to the trapezius and rhomboids. There is also another area of fat in the midline extending from the level of the 5th cervical 
vertebra to the 3rd thoracic: this fat lies on and in the superficial fascia.

\section{ZONE 2}

The superficial fascia in this zone is very vascular: fine hairlike vessels, which in the main run downwards and outwards, can be seen quite clearly. The skin is more adherent in this zone, except towards the sides of the body. The most striking feature is the fat, which is reddish in colour and constitutes the major portion of the basic fat. It is found to be in, rather than on, the superficial fascia; this consists of many layers or compartments in which the fatty tissue is contained. Its extent is as follows:

Medially.-The outer border of M. Sacrospinalis.

Laterally.-It is small in extent near its upper border, and expands laterally as it reaches the iliac crest, until its outer limit is some $2 \frac{1}{2}$ inches lateral to the outer border of M. Sacrospinalis.

Above. - The upper limit is approximately the level of the third lumbar vertebra.

Below.-It descends into Zone 3 for some 2 inches below the iliac crest and there covers that part of $M$. Gluteus medius which is not covered by $M$. Gluteus maximum. In addition to this fat there is also fat in the angle formed by the posterior and middle layers of the deep lumbar fascia where they unite to enclose M. sacrospinalis. This fat extends up to the point where $M$. Sacrospinalis is crossed by the lower border of $M$. Latissimus dorsi, presumably protecting the nerves and blood vessels which perforate this fascia where they are not covered by the latter muscle.

\section{ZONE 3}

The red fat in Zone 2 extends into this zone as described above: the rest of the fatty tissue here is yellow fat and is considerable in amount; it lies in and deep to the superficial fascia.

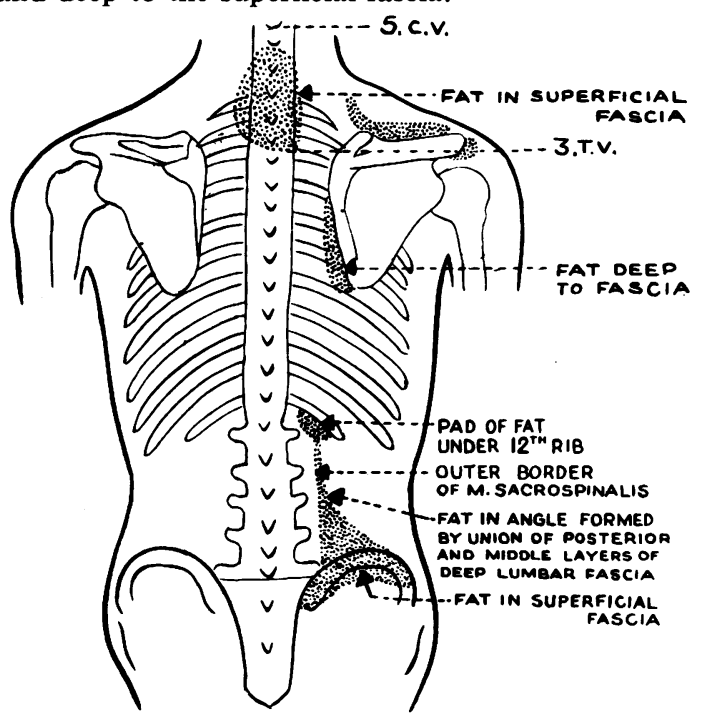

Fig. 1.

\section{Herniation of Fat}

In the fourth body dissected a herniation of fat from one layer of fascia to another was found, and many examples of this were observed in subsequent dissections. They were even brought on by pressure on either side of a weak spot in the fascia, and it seems clear that the pressure of a suddenly contracting muscle with the counter-pressure of underlying bone could easily produce and maintain herniation of fat lobules. The presence of these herniae and gaps in the fascia where herniation could easily occur suggests many possibilities. In twelve biopsies on selected patients suffering from clinical " fibrositis" of the back fatty lobules under tension or fatty herniae were discovered. Their removal resulted in cure in most cases and striking relief in those not completely cured. The presence of fat in the angle formed by the union of the posterior and middle layers of the deep lumbar fascia has been described; the posterior primary nerve roots pierce this fascia and are surrounded by fatty tissue. Congestion or oedema of this fat could obviously give rise to severe pain, and, furthermore, the edges of the ring of fascial opening might maintain these swollen lobules for a long time, resulting in permanent pathological change.

Herniae of fat may be divided into two broad groups: (1) Congenital.-Where a mass of fat passes through one or more layers of fascia through welldefined gaps; this was found many times in the course of the dissections. (2) Acquired.-This group can be further sub-divided into $(a)$ mechanical, and $(b)$ postural-e.g. lying in bed during long illness.

The mere presence of herniation will not by itself necessarily give rise to symptoms, and the probable sequence of events in those cases that do develop clinical "fibrositis" of the back is as follows. If herniation takes place by mechanical means-e.g. during violent physical exercise or unexpected contraction of certain muscles-the result will be (1) constriction of the blood vessels, leading to (2) oedema or haemorrhage in the fatty tissue: examination of sections of fatty nodules removed at biopsy confirm these views. This was clearly shown, in at least two patients, as one dated the onset of pain from an accident when playing rugby football, and another after throwing heavy cans into a lorry. In both cases herniating fatty nodules with evidence of haemorrhage were removed, with resultant cure.

Oedema is likely to arise in postural cases, and congestion may follow in febrile illnesses, which so often light up "fibrositis" in the back. An example of this type of case was furnished by a patient who developed acute fibrositis during an attack of infective hepatitis: at biopsy a large nonpedunculated herniating fatty lobule under considerable tension was excised with complete relief of symptoms. Many of the fatty lobules taken from other cases had fibrous pedicles, the pedicle often running from one fatty lobule to another. Sections of fatty lobules frequently showed young fibrous tissue growing into the adipose tissue; this, over a period of years, might lead to the formation of a pedicle. Once a pedicle has formed it is easy to visualize torsion of that pedicle taking place. The causes of pain and swelling in these herniae and fatty lobules which become painful nodules may, 
therefore, be (1) oedema, (2) haemorrhage, (3) congestion, (4) torsion of pedicle.

\section{Case Reports}

Four case reports of the many which were seen and had biopsy performed are included, as they illustrate herniation and pedicle formation, and the part played by mechanical and postural conditions in the aetiology of fibrositis of the back.

Case 1.-This patient gave a history of lumbago in 1942. He was in bed for 11 days and was discharged no better. Light duty worked off the pain in three or four weeks. The present attack started 16 days before admission. He had recently been driving a very stiff lorry which was difficult to start and in which there was a lot of vibration. On examination he had a very tender spot at the outer edge of M. Sacropinalis (R) at the level of the third lumbar vertebra. Slight thickening could be felt but no nodule could be palpated. At biopsy an incision was made over the tender spot and a finger introduced into the wound. No nodule could be felt but pressure reproduced the pain. When the deeper layers of the superficial fascia were exposed a small herniation, which felt tense and nodular, was seen to protrude throught it. This herniating fat was removed with a small area of fascia. After 14 days the patient was completely cured and discharged free from pain. Microscopical examination of a section showed fatty tissue with young very cellular fibrous tissue growing into it. The blood vessels were congested and there was some haemorrhage into the tissue. There were also areas of older fibrous tissue, probably the result of earlier inflammation or of trauma; and serous exudate into some of the fat spaces.

Case 2.-This patient had a history of intermittent pain in the back for fifteen years following an accident when playing football. The pain was lit up by damp weather, cold winds, attacks of influenza, etc. A tender spot over the crest of the right ilium could be palpated and local pressure reproduced the pain. An incision was made over the tender spot and a fat lobule found lying superficial to the gluteal fascia. This lobule had a vascular pedicle going through the fascia to another larger lobule lying deep to the fascia, among but distinct from the surrounding fat. Pressure on this evoked the pain. This tissue was removed and a complete cure resulteda freedom from pain hitherto unknown. The section taken from this tissue consisted of fatty material invaded by young and very cellular fibrous tissue. There were many patches of older fibrous tissue similar to those in the section from Case 1, but they were much more numerous. The nodule was relatively avascular, such nodules as were present being small and not congested.

Case 3.-This patient had a history of pain in the back of four years' duration, first noticed after sleeping on damp ground. The pain was in the left side of the back, radiating to the buttock, the back of the thigh, knee, and calf, and tended to recur with chills, etc. Rest in bed in hospital had given no relief. On examination there was an easily palpable nodule at the outer border of the Erector Spinae just above the level of the iliac crest, and pressure on this point reproduced the pain. On incision a tense nodule of fat the size of a cherry was found lying in the superficial fascia; it had a vascular pedicle which ran through the superficial fascia. The result of removal was complete freedom from pain.

Case 4.- This patient had a history of severe pain in the left buttock and down the back of the thigh for a year. The original cause was not known; there was no history of trauma or infection. The pain became worse when for any reason he had to lie in bed, and on this occasion flared up during an attack of infective hepatitis. On examination a tender nodule was found in the buttock 5 inches from the midline and $2 \frac{1}{2}$ inches below the iliac crest. An injection of $10 \mathrm{c.cm}$. of 1 per cent. novocain saline and teasing with a thick needle gave much relief, but the tender nodule was still present. An incision was made over the nodule and the fat in the superficial fascia was found to be in two or three layers, which were incised. Some lobules seemed to be under tension, bulging up into the wound when the septa were cut. One nodule the size of a pea was removed and the remainder teased and broken up; it appeared to be a non-pedunculated fat hernia. The patient was discharged 18 days later free from pain.

\section{Conclusions}

The constant occurrence of the basic-fat pattern in all the backs dissected, even in those which were very wasted and had little or no subcutaneous fat, suggests that the fatty tissues may play an important part in the pathology of "fibrositis" of the back. This supposition is further confirmed by the fact that in every case submitted to biopsy fatty tissue was removed with complete relief of symptoms.

The mechanism of herniation and the subsequent causation of symptoms may be classified as follows: A. Herniae of fat may be (1) Congenital; and (2) Acquired: (a) mechanical, $(b)$ postural. B. The causation of signs and symptoms from the hernia may be due to (1) Oedema, (2) Haemorrhage, (3) Congestion, (4) Torsion of Pedicle.

\section{Summary}

A composite description of the dissection of twelve backs is given with particular reference to the "basic" fat pattern and the occurrence of fatty herniations, particularly in this fat pattern. Four cases illustrating the possible aetiology and pathology of fibrositis of the back are recorded.

\section{REFERENCE}

Copeman, W. S. C., and Ackerman, W. L. Quart. J. Med., July,
1944 . 